\title{
"I Learned More About How I Should Not Behave": A Narrative of Experience in An Undergraduate Teaching Degree Course
}

\author{
Cláudia M. Bokel Reis ${ }^{1}$, William Soares Dos Santos ${ }^{2}$ \\ ${ }^{1,2}$ Federal University of Rio De Janeiro (Ufrj)
}

\begin{abstract}
From a perspective of analysis which considers the production of narratives as a discursive, dialogical, and ideological process (Bastos \& Santos, 2013) and discourse as a sociointerational construct (Gumperz, 2002), this research investigates the written narrative of a student of Portuguese Language Teaching Practice / Foreign Language of Degree in Letters of a Brazilian Federal University in Brazil in which she recounts her path during the Teaching Practice internship. In our research, we highlight excerpts from her narrative in which the teacher in formation is critical in relation to the behaviour of her regent teachers. The research favours understandings arising from the study of narratives and identity performances. We focus on how the student discursively constructs her experience of formation in supervised training and the possible meanings that emerge from this production. The results point to the need to reflect closely on the supervised internship process as a space for real action (and not just observation) in which the student has to prepare for the challenges of teaching. Another question that pertains our research is how we can better deal with the tensions between teachers in charge for the classes and teachers in training so that the experience of the Teaching Practice can include not only technical questions, but also didactic ones in its ethical and dialogical dimensions, always paying head to the training of the future language teachers so as to allow them to work in different teaching / learning spaces.
\end{abstract}

Keywords: Foreign Language Teaching, Teacher Training, Narrative Studies.

\footnotetext{
${ }^{1}$ Cláudia M. Bokel Reis is an Associate Professor at the College of Education of UFRJ, where she teaches Portuguese and English Teaching Practice.

${ }^{2}$ William Soares dos Santos is an Associate Professor at the College of Education of UFRJ, where he teaches Portuguese and Italian Teaching Practice. He is also Associate Professor at the Interdisciplinary Post Graduate Program in Applied Linguistics (PIPGLA) at the College of Letters of UFRJ.
} 